\title{
Management of gastrointestinal pain
}

\author{
Erin Malone, DVM, $\mathrm{PhD}^{\mathrm{a}, *}$, Lynelle Graham, DVM ${ }^{\mathrm{b}}$ \\ ${ }^{a}$ Department of Clinical and Population Sciences, University of Minnesota College \\ of Veterinary Medicine, 225K VTH, 1365 Gortner Avenue, St. Paul, MN 55108, USA \\ ${ }^{\mathrm{b}}$ Department of Small Animal Clinical Sciences, University of Minnesota College \\ of Veterinary Medicine, St. Paul, MN 55108, USA
}

Regular additions to the list of available analgesics have greatly eased the management of gastrointestinal dysfunction in the horse, and continuing research suggests that several more drugs are likely to be in use within the next decade. No drug comes without side effects, however. The increasing variety of products makes it more feasible to select the pharmaceutic agent providing the necessary analgesia with minimal complications. This review is designed to highlight the advantages and disadvantages of the drugs currently in use and as well as to provide information about some that may become more widely available in the near future.

Analgesic selection in horses with gastrointestinal dysfunction can be a critical point in case management. It is important to minimize perceived pain to the animal for its own sake as well as for that of the owner or caretaker. Additionally, a horse that is in pain is at risk of hurting itself and those around it. Providing at least short-term analgesia enables a better examination and more efficient treatment $[127,167]$. A poor or short duration of response to analgesics can also indicate a need for surgical exploration [38,61].

Pain can also have secondary effects on the animal. Continued pain leads to an increased metabolic rate and altered immune function, potentially leading to increased weight loss and delayed wound healing [115]. Pain may also lead to worsening of a primary gastrointestinal lesion by increasing reflexive adrenergic activity. Reduction of such pain-induced sympathetic tone may enable return to more normal motility and aid in the resolution of tympanic or impaction colic [172]. Control of pain may also minimize the incidence of impactions associated with rectovaginal lacerations and may be useful as a diagnostic tool, particularly when local analgesia is possible [113,171].

Many analgesics have anti-inflammatory properties as a primary or adjunctive mechanism of action. Release of inflammatory mediators is often

\footnotetext{
* Corresponding author.
} 
a factor leading to a pain response in horses. Inflammation also increases the sensitivity of nerve fibers to continued release of such mediators [115]. In other species, it has been demonstrated that inflammation can activate additional afferent neurons, leading to a stronger pain response and, in some cases, a painful response to normal stimuli [24]. In other instances, inflammation has been shown to alter $\alpha$-adrenoreceptor activity [24], which could alter afferent signaling (response to inflammation) and drug response. Inflammation and pain have been implicated in the development of postoperative ileus and human gastric dysfunction [24,75]; controlling one or both has been successful in several models at either preventing or treating the dysfunction $[65,75]$.

Analgesic use before and during surgery may also lessen the need for postoperative analgesics and pain- or drug-associated complications $[115,176]$. Preemptive and intraoperative analgesia decreases the number and amount of anesthetic drugs required, helps to stabilize anesthesia, and may decrease postoperative analgesia requirements and postoperative morbidity, including gastrointestinal-related complications [115,176].

Analgesics can also hinder case management, however. By masking pain or fever or altering hemodynamic status, these drugs can impair monitoring and obscure a need for abdominal exploratory or allow a case to worsen unnoticed [61]. In many instances, these horses are receiving several different drugs that may have significant interactions. Finally, many of the available analgesics are known to affect the gastrointestinal tract, potentially worsening the original dysfunction. As a result, it is important to select a product that provides the necessary analgesia without being excessive and to carefully monitor for drug-related side effects. Client education is an important aspect of the process so as to ease concerns about appropriate pain relief as well as to watch for subtle indications of drug-related problems.

Abdominal pain arises most commonly from intestinal distention, intestinal muscle contraction (spasm), mesenteric tension, intestinal ischemia, intestinal inflammation, or peritonitis $[61,114]$. Afferent sensory fibers may extend to other regions of the intestinal tract, to local ganglia, or to the spinal cord. Many of the drugs in use today have well-understood mechanisms of action. Many have been tested on models of colic pain, often using a model of cecal distention [114]. In this model, a balloon is inserted into the cecum and gradually distended until the horse shows evidence of discomfort. Analgesics are compared based on their ability to alter the discomfort threshold. Having one model makes drug comparisons much easier, but this model is subject to variation within and between animals [93,127].

\section{Nonsteroidal anti-inflammatory drugs}

Drugs that inhibit the release of prostaglandins are among the most commonly used analgesics for equine visceral pain. Phenylbutazone, dipyrone, 
ketoprofen, and flunixin meglumine are the most widely used nonsteroidal anti-inflammatory drugs (NSAIDs) [38,114]. These drugs are effective against inflammation-mediated pain sensation. They reduce the sensitivity of nerve endings to pain and likely have central effects as well (Table 1) [176].

Of this class, flunixin meglumine is believed to be among the most potent of visceral analgesics, and it is labeled for equine visceral pain $[38,128]$. In one study, $68 \%$ of 118 horses with medical colic showed a good to excellent response to the drug $(1.1 \mathrm{mg} / \mathrm{kg}$ administered intravenously) within 1 hour, and $38 \%$ of the 118 horses improved within 15 minutes [167]. More severe cases (moribund or preoperative) also showed improvement after administration of flunixin meglumine. In cases of mild to moderate colic in another study, a good to excellent response was obtained in $98 \%$ of the cases using $1.1 \mathrm{mg} / \mathrm{kg}$ of flunixin meglumine administered intravenously [7]. Flunixin meglumine also relieved clinical signs of colic for 30 to 60 minutes in ponies subjected to an experimentally induced pelvic flexure impaction [95]. The drug was not effective at relieving pain in a cecal distention model, likely because of lack of inflammation-mediated pain [77]. Flunixin meglumine may be given at $1.1 \mathrm{mg} / \mathrm{kg}$ intravenously up to every 8 hours in horses with visceral pain; however, it may be effective at a reduced dose $(0.25-0.5 \mathrm{mg} / \mathrm{kg})$ and at longer intervals (up to $24-36$ hours) $[38,128]$. Flunixin meglumine has the added advantage of having antiendotoxic properties at a low dose [149] as well as at $1.1 \mathrm{mg} / \mathrm{kg}[81,163]$, and it was better than either xylazine or butorphanol at maintaining bowel perfusion in anesthetized ponies $[155,163]$. Repeated high doses can potentially obscure a surgical lesion $[38,61,128]$. Besides altering signs of pain, flunixin alters mucous membrane color and relieves fever [128].

Ketoprofen is a newer NSAID that has been demonstrated to have analgesic effects similar to those of flunixin meglumine in cases of musculoskeletal and visceral pain when administered at $2.2 \mathrm{mg} / \mathrm{kg}$ intravenously or intramuscularly [7,52]. A higher dose $(3.63 \mathrm{mg} / \mathrm{kg})$ has been suggested for

Table 1

Equine analgesics commonly used for visceral pain

\begin{tabular}{ll}
\hline Drug & Recommended dose \\
\hline Flunixin meglumine & $0.25-1.1 \mathrm{mg} / \mathrm{kg}$ IV every $8-24$ hours \\
Ketoprofen & $2.2-3.63 \mathrm{mg} / \mathrm{kg}$ IV or IM every 24 hours \\
Phenylbutazone & $\leq 4.4 \mathrm{mg} / \mathrm{kg} \mathrm{IV}$ or PO every 12 hours \\
Xylazine & $0.23-1.1 \mathrm{mg} / \mathrm{kg}$ IV $2.2 \mathrm{mg} / \mathrm{kg} \mathrm{IM}$ \\
Xylazine plus butorphanol & $1.1 \mathrm{mg} / \mathrm{kg}$ of xylazine IV plus $0.1 \mathrm{mg} / \mathrm{kg}$ of butorphanol IV \\
Detomidine & $0.005-0.04 \mathrm{mg} / \mathrm{kg}$ IV \\
Detomidine plus & $0.01 \mathrm{mg} / \mathrm{kg}$ of detomidine IV plus $0.05 \mathrm{mg} / \mathrm{kg}$ of butorphanol IV \\
$\quad$ butorphanol & $0.1-0.4 \mathrm{mg} / \mathrm{kg}$ IV of IM \\
Butorphanol & $1.3 \mathrm{mg} / \mathrm{kg}$ by bolus IV plus $0.05 \mathrm{mg} / \mathrm{kg} / \mathrm{min}$ by infusion IV \\
\hline
\end{tabular}

$\mathrm{IV}=$ intravenously, $\mathrm{IM}=$ intramuscularly, $\mathrm{PO}=$ orally. 
laminitis cases but has not been evaluated for equine visceral pain [21]. Ketoprofen has been shown to have antiendotoxic activity similar to that of flunixin meglumine [111]. In the horse, ketoprofen seems to have a much wider therapeutic margin than most NSAIDs. No evidence of toxemia was seen after ketoprofen was given to horses at five times the recommended dose for 15 days [52], and it showed fewer side effects than either phenylbutazone or flunixin meglumine [97].

Phenylbutazone is considered less effective for equine visceral pain than flunixin meglumine [172]. It is more effective than flunixin meglumine at reversing endotoxin-mediated disruption of gastrointestinal motility, however [81]. Phenylbutazone is less effective at altering the cardiovascular effects of endotoxemia, and it has been suggested that use of phenylbutazone for treatment of colic would avoid the potential problems of masking such clinical signs of endotoxemia [81]. It should not be given above $4.4 \mathrm{mg} / \mathrm{kg}$ every 12 hours because of its higher toxicity risk [97]. When phenylbutazone and flunixin meglumine are combined, the pharmacologic effect of each may be prolonged. In one study, serum thromboxane $\mathrm{B}_{2}$ production was suppressed for 8 hours after phenylbutazone, for 12 hours after flunixin meglumine, and for 24 hours after a combination of the two [148]. Combining NSAIDs may increase the potential for toxicity [128].

Dipyrone is no longer available but has been useful historically for horses with abdominal pain, particularly those with spasmodic colic [114]. Experimentally, it has been shown to antagonize bradykinin-induced intestinal spasm, but it did not alter normal activity or reverse spasm caused by nerve stimulation or cholinergic drugs [50]. It was not useful in cecal balloon distention models [93]. In general, dipyrone is considered a weak but safe analgesic in the horse $[38,61,172]$.

Other NSAIDs have been evaluated for their analgesic properties in the horse, however, not in terms of visceral analgesia (Table 2). When evaluating new drugs, it is important to remember that most NSAIDs have been shown to concentrate at sites of inflammation; plasma levels and duration of persistence may not correlate with therapeutic effect [21]. Additionally, if a pain model does not involve an inflammatory process, the analgesic effects of these drugs may not be accurately reflected.

In terms of direct effects on equine intestinal function and viability, flunixin meglumine is the best studied of the NSAIDs. Particularly when compared with other analgesic classes, it has been regarded as having no significant effect on normal intestinal motility. Flunixin meglumine did not alter mechanical or myoelectric activity of the pony jejunum or pelvic flexure [68,95], had only minimal effect on the colon [90], and did not alter intraluminal pressure changes in the cecocolic area or in a pelvic flexure impaction model $[95,140]$. Neither flunixin meglumine nor ibuprofen altered the gastrocolonic reflex [136], and neither dipyrone nor flunixin meglumine altered intestinal transit time in normal horses [101]. Although flunixin meglumine $(1.1 \mathrm{mg} / \mathrm{kg}$ administered intravenously) increased systemic vascular 


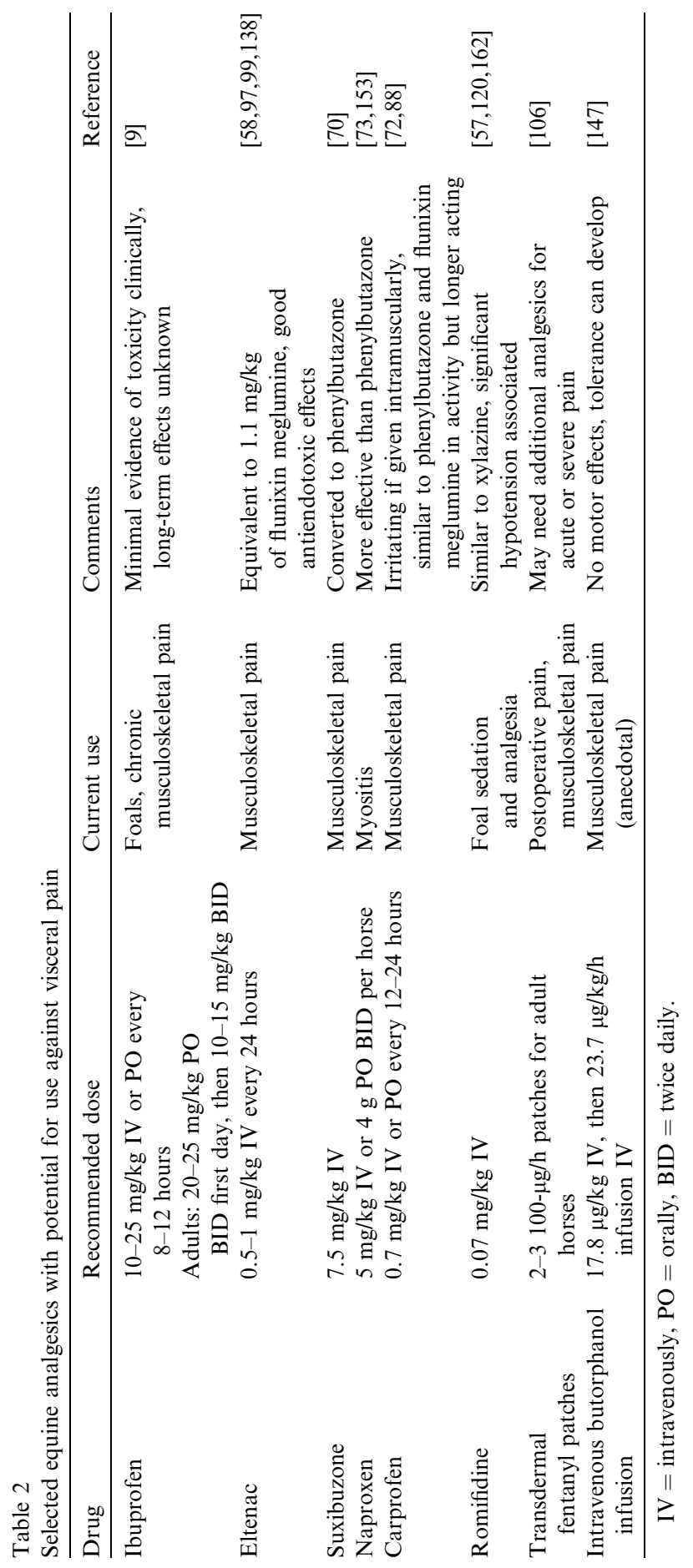


resistance, it did not alter jejunal blood flow in the same time frame and did not alter colic artery flow in a pelvic flexure impaction model $[95,156]$. It is subsequently believed not to compromise intestinal viability because of changes in vascular perfusion [156]. This may not be true of all NSAIDs [45]. More recent studies have raised additional concerns. Several NSAIDs did alter colonic contractility in vitro [166], and flunixin meglumine (but not etodolac) impaired mucosal healing because of inhibition of normal prostaglandin function [14].

Other reported gastrointestinal side effects of this class of drug include gastric ulceration, small intestinal edema, protein-losing enteropathy, and erosions and ulcers of the large intestine [15,97]. Foals seem to be particularly sensitive to development of diarrhea and phenylbutazone toxicosis $[15,21]$. At higher doses $(8.8 \mathrm{mg} / \mathrm{kg}$ administered orally twice daily for 10 days), phenylbutazone has been associated with anorexia, weight loss, diarrhea, and oral ulcerations [23]. Phenylbutazone has also been implicated in the development of right dorsal colitis [12] and has been shown to alter colonic ion transport in vitro, potentially leading to $\mathrm{pH}$ changes in the horse [43]. In a study comparing phenylbutazone, flunixin meglumine, and ketoprofen, phenylbutazone had the greatest toxic potential and ketoprofen had the least [97].

As mentioned previously, monitoring of horses with abdominal pain is inhibited by these drugs through their ability to alter body temperature, mucous membrane color, and hemodynamic parameters [128]. These drugs do not result in ataxia or sedation, however, as do many of the other analgesics, making them useful for analgesia during surgical recovery and in similar situations [72]. These drugs are highly protein bound and can displace other protein-bound drugs, leading to an increase in activity of the displaced drugs [21]. This can be of particular concern during the anesthetic maintenance and recovery periods.

In summary, ketoprofen may replace flunixin meglumine as the primary NSAID used in the treatment of gastrointestinal pain in horses; dosage and frequency of administration remain to be optimized. Horses requiring repeated doses of either ketoprofen or flunixin meglumine may have more severe gastrointestinal dysfunction and should be considered potential candidates for surgical exploration. Supportive treatment to minimize gastric ulceration and renal dysfunction should be considered. Concern over the effects of current drugs on gastrointestinal function and healing persist and may lead to replacement of these drugs with newer NSAIDs. NSAIDs are the primary drugs available at this time for the management of chronic visceral pain in the horse.

\section{Sedative analgesics}

The combination of sedation with analgesia can be useful in the evaluation of horses with abdominal pain. The $\alpha_{2}$-adrenergic receptor agonists 
such as xylazine and detomidine are potent as sedatives and as analgesics. They are faster acting but have a shorter duration of action than the NSAIDs [21,38]. In a pelvic flexure impaction model, xylazine $(0.23 \mathrm{mg} / \mathrm{kg}$ administered intravenously) relieved clinical signs for 30 to 60 minutes [95]. In other experimental models using $1.1 \mathrm{mg} / \mathrm{kg}$ administered intravenously or $2.2 \mathrm{mg} / \mathrm{kg}$ administered intramuscularly, analgesia has been reported to last from 65 minutes to 4 hours $[77,93,116]$. Clinical use at 1.1 $\mathrm{mg} / \mathrm{kg}$ administered intravenously suggests maximum effect at 3 minutes and a duration of 10 to 40 minutes depending on the severity of the pain [64]. Multiple studies using a cecal distention model of colic have shown that xylazine is better at relieving visceral pain than the tested opioids or NSAIDs, including flunixin meglumine, butorphanol, and morphine [77,93,116].

Combining xylazine with an opioid has been shown to give synergistic effects. When $1.1 \mathrm{mg} / \mathrm{kg}$ of xylazine was combined with $0.055 \mathrm{mg} / \mathrm{kg}$ of fentanyl, it provided more effective analgesia in a cecal distention model of visceral pain than did xylazine alone for up to 4 hours [127]. Xylazine $(1.1 \mathrm{mg} / \mathrm{kg}$ administered intravenously) combined with butorphanol $(0.1 \mathrm{mg} / \mathrm{kg}$ administered intravenously) better permitted flank laparotomy than did xylazine alone, with four of six horses comfortable for 30 minutes [134]. The analgesic effects of $0.1 \mathrm{mg} / \mathrm{kg}$ of butorphanol in a cecal balloon model were extended from 45 to 120 minutes when it was combined with $0.3 \mathrm{mg} / \mathrm{kg}$ of xylazine [117]. Acepromazine may also enhance the effects of xylazine, but because of its hypotensive effects, it is not recommended for use in most cases of gastrointestinal pain [61].

Detomidine is more potent and longer lasting than xylazine at doses greater than $0.005 \mathrm{mg} / \mathrm{kg}$ [21]. It has been shown to be effective in controlling visceral pain in horses [94]. Generally intravenous doses of 0.02 to 0.04 $\mathrm{mg} / \mathrm{kg}$ are recommended, with the duration of activity being dependent on the dose $[21,94]$. In a cecal balloon distention model, the duration of action of detomidine was 13.5 minutes at $0.005 \mathrm{mg} / \mathrm{kg}, 45.5$ minutes at $0.02 \mathrm{mg} / \mathrm{kg}$, and 239 minutes at $0.16 \mathrm{mg} / \mathrm{kg}$ [94]. Increased sedation, decreased responsiveness, and increased ataxia were reported when detomidine $(0.01 \mathrm{mg} / \mathrm{kg})$ was combined with opioids [22]. If used in combination, butorphanol at $0.05 \mathrm{mg} / \mathrm{kg}$ was recommended [22].

Medetomidine, romifidine, dexmedetomidine, and radolmidine are newer drugs in this class. Romifidine $(0.07 \mathrm{mg} / \mathrm{kg}$ administered intravenously) was more effective at allowing nasogastric tube passage in foals than was xylazine and provided a slightly longer period of analgesia [120]. In other studies, romifidine provided less analgesia and less sedation than xylazine or detomidine [57]. It has also been shown to have more significant hypotensive effects, making it riskier for use in many horses with colic [162]. At this time, medetomidine $(0.004-0.01 \mathrm{mg} / \mathrm{kg}$ administered intravenously) does not seem to provide a significant sedative advantage compared with xylazine in the horse and has been associated with increased ataxia and prolonged blood pressure effects $[13,61]$. Dexmedetomidine has become increasingly popular 
in human medicine because of simultaneous analgesia, sedation, and lack of respiratory depression [56]. When given intravenously $(0.1-10 \mu \mathrm{g} / \mathrm{kg})$ to goats, dexmedetomidine caused short-duration ( $<15$ minutes) vasoconstriction, while maintaining balanced myocardial oxygen supply and demand [86]. This may allow dexmedetomidine to be a useful analgesic sedative for cardiovascularly compromised colic. Radolmidine seems to be most effective as an antinociceptive agent when given intrathecally as compared to epidurally or systemically in sheep [39]. When given intrathecally, this drug is not associated with significant sedation, motor effects, or hemodynamic depression in other species [39].

Most, if not all, $\alpha_{2}$-adrenergic receptor agonists can mask surgical pain. The effects of xylazine are generally short-lived, particularly in severe cases. Larger doses of detomidine $(\geq 0.02 \mathrm{mg} / \mathrm{kg})$ can suppress pain for several hours [61]. The use of detomidine in horses with abdominal pain may alter the decision for surgery, either by delaying it because of minimal pain signs $[21,38,82]$ or by hastening the process because of the concern about missing a surgical lesion in a detomidine-treated horse.

Xylazine and detomidine have been found to have significant effects on the gastrointestinal tract directly and indirectly. Xylazine caused changes (primarily decreases) in the myoelectric activity of the stomach, small intestine, cecum, large colon, and small colon of normal ponies [20,68,69,90, $135,140,142]$. In the stomach, the alterations are reflected in decreased gastric emptying [36]. Xylazine was also found to reset the duodenal motility pattern and suppress intraduodenal pressure peaks [108,109]. Conversely, despite significant decreases in activity, cecal emptying was minimally affected at a dose of $0.5 \mathrm{mg} / \mathrm{kg}$ administered intravenously [90]. The duration of activity changes is dependent on the dose, with higher doses $(1.1 \mathrm{mg} /$ $\mathrm{kg}$ administered intravenously) lasting up to 120 minutes [20]. The effect on the cecum was prolonged (150 vs 120 minutes) when xylazine was combined with $0.1 \mathrm{mg} / \mathrm{kg}$ of butorphanol [142]. Similar prolonged effects were seen with morphine in the cecocolic region [140] and in the duodenum with a combination of $0.5 \mathrm{mg} / \mathrm{kg}$ of xylazine and $0.05 \mathrm{mg} / \mathrm{kg}$ of butorphanol [108]. In the duodenum, the inhibition of normal contractions increased from 30 minutes with xylazine alone to 60 minutes with both drugs and was more markedly changed with the latter. In a pelvic flexure impaction model, xylazine $(0.23 \mathrm{mg} / \mathrm{kg}$ administered intravenously) stopped intraluminal pressure changes for 30 minutes [95]. Detomidine can also alter activity in the duodenum, large intestine, and cecum (only areas tested), with the duration of changes lasting up to 3 hours [108,135]. Clinically, decreased gastrointestinal sounds have been noted with both drugs [21], and xylazine and detomidine reversed diarrhea caused by administration of prostaglan$\operatorname{din} F_{2 \alpha}$ [135]. The newer drugs in this class have been shown to cause similar inhibition of gastrointestinal motility in other species $[4,118]$. In other species, $\alpha_{2}$-adrenergic receptor agonists also increase the absorption of fluid and electrolytes from the intestine [17]; this potential effect has not been 
evaluated in the horse. Although these changes have the potential of slowing gastrointestinal motility and worsening impactions, they may also help to relieve intestinal spasm and pain $[68,172]$. Finally, the response to $\alpha_{2}$-adrenergic receptor agonists seems to be altered in some horses with naturally occurring colic and in bowel adjacent to areas of ischemia, making the effects of these drugs potentially different in these animals than in normal horses [103]. The gastrointestinal effects of the drugs can be reversed at least in part by tolazoline or yohimbine, but the analgesic activity is reversed as well $[54,109,135]$. Tolazoline and yohimbine have also been shown to alter normal intestinal activity [90,109].

The hemodynamic changes associated with $\alpha_{2}$-adrenergic receptor agonists are believed to significantly affect the gastrointestinal tract as well. Lateral cecal arterial blood flow was decreased to a greater extent than was cardiac output in normal ponies, and colic arterial blood flow was decreased rather than increased in a pelvic flexure impaction model [95,142]. The durations of cecal blood flow changes were dependent on dose and were not significantly different when butorphanol was added to the xylazine [20,142]. Local intra-arterial injection of xylazine into the jejunum of ponies resulted in a combination of vasoconstriction, increased activity, and increased oxygen use, which would suggest that it could have a negative effect on bowel viability [155]. The effects of repeated xylazine in this study were increased and prolonged; however, because most of the effects of xylazine are mediated centrally, the clinical contribution of local drug effects is unknown.

Care should be taken with these drugs in animals that are febrile (alteration in thermoregulatory mechanisms) or in shock because of the potential cardiovascular effects $[128,172]$. One nervous stallion with colic died after receiving xylazine $(1.1 \mathrm{mg} / \mathrm{kg})$, and acute collapse has been reported in other horses [44,51]. Horses under apparent heavy sedation can still be aroused and kick $[64,128]$. Detomidine or xylazine combined with an opioid such as butorphanol provides a better balanced stance (and is safer for procedures near the hindquarters) than does xylazine alone [46,105]. Behavior changes can occur with both drugs, including increased aggression (Internet communication, John Madigan, DVM, MS, 1996) [175]. Clinicians should be aware of potential interactions of $\alpha_{2}$-adrenergic receptor agonists with other drugs, particularly those undergoing hepatic metabolism. Clinical ileus was prolonged in a horse treated with xylazine and chloramphenicol, and the combination of intravenous potentiated sulfonamides and detomidine can result in fatal arrythmias [54,128].

In summary, xylazine and detomidine are strong analgesics that can alleviate most equine visceral pain at least temporarily. Because of its shorter duration of action, xylazine is preferred in situations where assessment of the need for surgery is ongoing. Detomidine may be required to provide sufficient analgesia in some situations or if surgery is not an option. Careful communication with the owner and any referral institution is necessary to ensure appropriate case care and humane treatment. Repeated doses most likely 
have significant clinical effects on gastrointestinal motility and blood flow. Decreasing doses of xylazine and detomidine with the addition of butorphanol may minimize effects on blood flow but may not diminish motility alterations.

\section{Opioid analgesics}

Several opioid analgesics have been evaluated in the horse. Most commonly, drugs from this group are combined with sedative analgesics to increase the analgesic effect and duration of action of those compounds as discussed previously. The opioids do have some analgesic effect when given alone, but because of excitatory effects, they need to be given at a low dose or combined with another drug [128]. In horses experiencing pain, the excitatory effects may be less evident, however [46].

In cecal balloon distention models, butorphanol was effective at relieving pain for 10 to 45 minutes at doses of $0.1 \mathrm{mg} / \mathrm{kg}$ and higher [117]. A dose of

$0.2 \mathrm{mg} / \mathrm{kg}$ of butorphanol administered intravenously provided adequate pain relief for at least 60 minutes, and a dose of $0.4 \mathrm{mg} / \mathrm{kg}$ administered intravenously provided adequate pain relief for 90 minutes $[76,77,116]$. Experimentally, butorphanol has been found to be more effective than meperidine, morphine, methadone, levorphanol, and pentazocine at reducing equine visceral pain $[76,77,93,116,117,127]$. Clinically, butorphanol administered intravenously at a dose of $0.1 \mathrm{mg} / \mathrm{kg}$ provided good to excellent analgesia in $93 \%$ of colic cases [158]. Oxymorphone (10 $\mathrm{mg}$ for an adult horse) and morphine $(0.66 \mathrm{mg} / \mathrm{kg})$ have also been used successfully to manage colic pain in horses [30,124].

Recently, transdermal fentanyl patches and continuous intravenous butorphanol infusion have been investigated in the horse for general pain relief. A butorphanol infusion rate of $23.7 \mu \mathrm{g} / \mathrm{kg} / \mathrm{h}$ after a loading dose of $17.8 \mu \mathrm{g} / \mathrm{kg}$ resulted in plasma concentrations that would be expected to give pain relief, and no behavioral side effects were observed [147]. The authors have successfully used a butorphanol infusion to provide relief from musculoskeletal pain but have observed the development of tolerance after approximately 48 hours. Transdermal fentanyl patches in the horse have been reported to result in rapid absorption of fentanyl, with plasma levels reaching levels greater than $2 \mathrm{ng} / \mathrm{mL}$ in only 4 hours [106]. Levels remained above $1 \mathrm{ng} / \mathrm{mL}$ for 54 hours and fell rapidly after patch removal. Although effective analgesic levels of fentanyl are not reported in the horse, effective analgesic levels for human beings are reported to be greater than $1 \mathrm{ng} / \mathrm{mL}$. Based on the single reported study of fentanyl patch use in the horse, significant plasma levels were achieved in adult horses (mean body weight of $381 \mathrm{~kg}$ ) with the application of two $100-\mu \mathrm{g} / \mathrm{h}$ patches [106]. Larger horses may require the placement of three $100-\mu \mathrm{g} / \mathrm{h}$ patches. Tolerance may be less of a problem than with other opioids [115]. Fentanyl patches are effective for 
the relief of chronic pain, dull pain, and nonspecific widespread pain. Additional drugs may be required in animals with acute or severe pain. Butorphanol should not be used in combination with fentanyl because of its mixed agonist-antagonist effects, which could reverse the analgesic effects of the patch [115]. At the level of use reported, no adverse behavioral effects or changes in heart rate were attributed to the fentanyl [106]; however, delayed hair growth and changes in hair color have been anecdotally associated with fentanyl patch use.

Opioids are well known for their gastrointestinal side effects. Decreased gastrointestinal sounds, fecal passage, and constipation have been reported at a dose of $0.1 \mathrm{mg} / \mathrm{kg}$ of butorphanol administered intravenously [21,147]. Gastric emptying in normal ponies was delayed by $0.05 \mathrm{mg} / \mathrm{kg}$ of butorphanol administered intravenously, but the effect was short-lived [36], and minimal effect was detected on antroduodenal activity [110]. No overall decrease in transit time of a liquid marker was detected at a dose of $0.1 \mathrm{mg} / \mathrm{kg}$ administered intravenously [133]. This butorphanol dose did disrupt propulsive activity of the jejunum but did not affect the pelvic flexure [152]. Conversely, morphine significantly prolonged transit of a liquid marker in ponies at a dose of $0.4 \mathrm{mg} / \mathrm{kg}$ or higher administered intramuscularly [133]. In the same study, intestinal sounds were reduced, feces were drier, and abdominal discomfort occurred at higher doses of morphine. The combination of xylazine and morphine was reported to result in ileus and abdominal pain when used for standing analgesia [82]. Fentanyl $(0.01-0.05 \mathrm{mg} / \mathrm{kg}$ administered intravenously) inhibited cecocolic propulsive activity in a dose-dependent manner and closed the cecocolic sphincter for 1 to 2 hours [137]. Combined with a potential for antisecretory activity as seen in other species, the motility effects of repeated dosing of these drugs could lead to an increased risk of impaction [11,172]. Recent work in mice suggests that inflammation leads to an upregulation of opioid receptors $(\delta>\mu>\kappa)$ and increases the gastrointestinal effects of these drugs [165]. Butorphanol does not seem to impair oxygenation of bowel, however, and should not compromise intestinal viability [157]. The gastrointestinal side effects of these drugs can be reversed with naloxone (along with analgesic effects); however, naloxone can also cause abdominal distress in horses [79,133,172].

In summary, opioids are useful adjuncts for analgesia in the horse, particularly when combined with $\alpha_{2}$-adrenergic receptor agonists; however, their use may not alleviate changes in gastrointestinal function, and chronic use may lead to fecal drying and impactions. Additionally, newer methods of administration may enhance the use of these drugs. Transdermal fentanyl patches may offer a cost-effective method for relief of more chronic pain in the horse.

\section{Local anesthetics}

Intravenous lidocaine has been used as an analgesic in people for decades and is now being used in the horse to provide pain relief [34]. Low-dose 
continuous lidocaine infusion was found to decrease postoperative pain scores and the amount of narcotics required after cholecystectomy and prostate surgery in people $[53,130]$. In ponies, intraoperative lidocaine decreased the halothane minimum alveolar concentration in a dose-dependent manner when given intravenously at 0.05 or $0.1 \mathrm{mg} / \mathrm{kg} / \mathrm{min}$ after a loading dose of 2.5 or $5 \mathrm{mg} / \mathrm{kg}$ [34]. A related compound was reported to be effective in the treatment of colic over 30 years ago [100]. Intravenous lidocaine has been used anecdotally for the treatment of various impactions, including cecal impactions, in the horse $[102,125]$. Lidocaine enemas are used to prevent and treat rectal tears [144]. Lidocaine has also been used intragastrically in horses with gastrointestinal ulcers as a diagnostic tool to determine if colic pain was caused by the ulcers or another lesion (T. Ames, DVM, MS, personal communication, 2001).

In the human studies described previously, lidocaine infusion had the additional beneficial effects of decreasing the duration of postoperative paralytic ileus and shortening hospital stays [53,130]. This may occur directly or through interruptions of reflexive responses to pain, endotoxemia, or inflammation $[53,98,146,170]$. Lidocaine has been used to treat postoperative ileus and proximal duodenitis jejunitis in horses with moderate success at a dose of $0.05 \mathrm{mg} / \mathrm{kg} / \mathrm{h}$ after a loading dose of $1.3 \mathrm{mg} / \mathrm{kg}$ [104]. At this dose rate, the analgesic effect is sufficient to mask signs of laminitis. The same dose rate has been used by the authors to treat severe cases of laminitis with good results and no evidence of tolerance.

At higher doses, lidocaine can cause central nervous system (CNS) excitement, including seizures [25]. In horses, muscle fasciculations and ataxia were detected at blood levels over $2.4 \mathrm{mg} / \mathrm{L}$ (E. Malone, DVM, PhD, unpublished observations), and seizures can occur at blood levels above $6 \mathrm{mg} / \mathrm{L}$ [34]. In a few cases, ataxia was associated with collapse. Lidocaine has a short half-life, however, and horses recover from side effects within minutes when the infusion is stopped or slowed. In a multicenter trial using lidocaine for reflux, major concerns related to the lidocaine included a potential increase in the incisional infection rate and masking of early signs of laminitis [104]. Direct effects of lidocaine on the equine pylorus [121] or jejunum have not been detected in vitro (E. Malone, DVM, PhD, unpublished observations); however, lidocaine was shown to increase contraction amplitude of the proximal duodenum of normal horses [121]. Lidocaine plasma levels can be increased by the concurrent administration of other drugs utilizing the hepatic cytochrome P450 system such as cimetidine and metronidazole.

In summary, intravenous lidocaine may be useful for the treatment of gastrointestinal pain in horses; however, close monitoring of the constant infusion rate is required to ensure efficacy and minimize toxicity. The ability of the drug to relieve severe pain likely masks the need for surgery, and horses being treated with this drug require close monitoring and occasional withdrawal of the drug to assess true pain status. It may be most useful in alleviating pain-induced sympathetic inhibitory tone and restoring normal 
motility in cases of impactions or ileus. Local use may become more prevalent as we investigate its potential in the horse.

\section{Epidural analgesia}

Epidurals have long been used to alleviate abdominal pain in human beings, and epidural local anesthetic administration is associated with improved gastrointestinal function in people when compared with epidural or systemic opioids [1,154]. In horses, effective epidural analgesia has been obtained for hind limb but not forelimb pain [35,161]. Epidural morphine delivered at the lumbosacral space offered adequate postoperative analgesia for thoracotomies in dogs [126], implying that abdominal analgesia might also be achieved in veterinary patients. Although epidural morphine is thought to be helpful in alleviating abdominal pain in some species, the effects in horses remain unclear. Most likely, epidural catheters would be required to deliver the analgesic drugs in horses.

Local anesthetics have typically been used in horses for caudal epidural analgesia, and to achieve abdominal analgesia without significant hind limb motor blockade would be nearly impossible. Local anesthetics with fewer motor effects are now available for epidural administration in people. Ropivacaine, one of the new amide local anesthetics, seems to offer a lower risk of cardiovascular and CNS toxicity [143]. Although the analgesia is the same or slightly shorter with epidural ropivacaine, the motor blockade is less intense than with bupivacaine [10]. In a study comparing epidural ropivacaine and bupivacaine for abdominal surgery in human patients, no difference was seen in effects on gastrointestinal function after surgery [74]. Levobupivacaine, the $\mathrm{s}(-)$ enantiomer of bupivacaine, also offers a lower risk of cardiovascular and CNS toxicity [42]. The analgesia associated with epidural levobupivacaine is similar to or longer than that of bupivacaine, with less pronounced motor blockade. Epidural levobupivacaine offers good analgesia for human patients undergoing abdominal surgery [84], and the addition of morphine potentiates the efficacy of epidural levobupivacaine [26].

\section{Broodmares and neonates}

Most drugs given to broodmares can have potential adverse effects on the fetus and neonate. Opioids may cross the placenta readily and can lead to fetal cardiovascular and respiratory depression [46,128], primarily a concern if a cesarean section is required. In people, chronic opioid use is associated with low - birth weight infants, behavioral deficits, and increased neonatal mortality. Opioids also have the potential for altering milk letdown and maternal behavior, but clinically noticeable differences have not been detected in other species [37]. In cattle, xylazine increases intrauterine pressure and is believed to have abortigenic capabilities [87]. In horses, no specific effects of 
the drug were detected in eight mares given $20 \mu \mathrm{g} / \mathrm{kg} / \mathrm{wk}$ from day 14 to day 60 of gestation and then every 4 weeks until parturition [80]. Similarly, repeated detomidine doses caused temporary (90-minute duration) decreases in fetal heart rates but had no observed detrimental effects on the pregnancy [96]. Because of its high lipophilicity, dexmedetomidine leaves the maternal circulation quickly, and little drug is transported to the fetal circulation in people [2]. This characteristic may make dexmedetomidine a desirable drug for analgesia and sedation in pregnant mares. Only small amounts of phenylbutazone were detected in the milk of mares being treated, and no phenylbutazone was detected in the foals [27]. Phenylbutazone does cross the placenta, however, and the half-life of the drug is longer in neonatal foals [28]. Young foals may also be more sensitive to the toxic effects of phenylbutazone [21,27], and foals have been born with gastric ulceration and renal failure apparently related to in utero exposure. In other species, NSAIDs can lead to fetal malformations if used in early gestation, and in late gestation, they can lead to premature closure of the ductus arteriosus and delayed onset of labor [37]. Recent evidence that NSAIDs can alter bone and cartilage development could also be a concern in fetal development [123,138]. Conversely, flunixin meglumine helps to decrease endotoxin-induced luteolysis in early gestation [163]. In people, lidocaine does cross the placenta, but fetal levels are generally $50 \%$ to $70 \%$ of maternal levels, and although neonates seem to be more sensitive to the drug, no differences were detected if fetal blood levels were less than $2.5 \mu \mathrm{g} / \mathrm{mL}[145,150]$. With the low doses used in horses for analgesia, fetal effects should be minimal.

\section{Older horses}

Drugs such as flunixin meglumine and phenylbutazone have been documented to have longer half-lives in older horses, perhaps because of changes in hepatic metabolism and protein binding [71,148]. The risk of toxicity may be lowered by increasing the interval between drug doses and by monitoring protein and renal parameters. Hepatic or renal dysfunction alters the metabolism of all major drugs discussed in this review and warrants additional monitoring and careful consideration of interval and dose.

\section{Trauma, shock, and after exercise}

No studies have been done on horses with gastrointestinal pain after strenuous exercise or significant trauma or other shock. Xylazine and detomidine were recently shown to provide safe and effective sedation after exercise when given at twice the normal dose to horses exercised on a treadmill; however, the drugs did lead to a prolonged increased body temperature [67]. Trauma to the abdomen can result in painful conditions that require analgesics to allow safe evaluation of the animal. These horses are at risk 
of increased drug-related side effects because of poor organ perfusion and circulating blood volume. Analgesics with cardiopulmonary effects (e.g., xylazine, detomidine) or with lower toxicity thresholds (NSAIDs) should be used sparingly until vascular perfusion is improved. Combinations of drugs such as xylazine and butorphanol can provide analgesia with lower doses of agents that have nonadditive side effects. Opioids are generally safest to use in shocky animals but should be used judiciously in patients with suspected head trauma and respiratory depression [126].

\section{Drug interactions}

Many horses with gastrointestinal pain may be receiving other drugs besides analgesics, including antibiotics, antiulcer medications, antiendotoxic drugs, or motility modifiers. Horses undergoing anesthesia are subject to additional classes of drugs and additional adverse cardiovascular effects such as hypotension. Many of the drugs have overlapping toxicities or can affect the metabolism of other agents. Renal toxicity is of increased concern when NSAIDs are used in combination with each other or with antibiotics such as gentamicin, polymyxin B, or the cephalosporins [47,128]. Phenylbutazone may increase the plasma half-life of penicillin, and the combination of phenylbutazone and heparin may increase the risk of bleeding disorders [128]. Most NSAIDs are also highly protein bound and can displace other protein-bound drugs. This can alter anesthetic planes if NSAIDs are given during surgery or in recovery. The combination of an aminoglycoside, lidocaine, and polymyxin B could lead to enhanced neuromuscular blockade [59]. Fatal dysrhythmias may also occur when detomidine is used in combination with potentiated sulfonamides [128]. Drugs that alter hepatic microsomal enzymes can change the metabolism of other similar drugs, leading to potential toxicity when drugs such as phenylbutazone, lidocaine, diazepam, cimetidine, metronidazole, and omeprazole are used in combination $[59,128]$. If a potential for toxin ingestion exists, drugs that are known to slow intestinal transit time such as the opioids should be avoided until the toxin is eliminated from the gastrointestinal tract [128].

As mentioned previously, analgesic combinations may also be synergistic. Recent work suggests that not only are opioids synergistic with $\alpha_{2}$-adrenoceptor agonists but that they may also be synergistic with local anesthetics and with NSAIDs $[19,83]$. Conversely, combinations of opioids of different classes can hinder pain relief because of the reversal of agonists such as fentanyl by agonist-antagonists such as butorphanol [46].

\section{Herbal therapy}

A paucity of information exists regarding the use of herbs in horses, especially for the treatment of gastrointestinal disease. Nevertheless, certain 
herbs are thought to have anti-inflammatory, antispasmodic, or analgesic effects in a variety of species. Ginger (Zingiber officinale) is an effective antiemetic [168] and possesses gastroprotective effects [179]. It is commonly used in the treatment of gastric ulceration and gastritis and could be useful in foals with gastric ulcers. Dai-Kenchu-To (containing xanthoxylum, ginseng, and ginger) inhibits distal colonic contractions in the rat and is commonly used to treat paralytic ileus in Japan [164]. Peppermint oil relaxes gastroin testinal smooth muscle via a reduction in calcium influx [63], and clinically effective enteric-coated and non-enteric - coated preparations of peppermint-caraway oil are commercially available [112]. Lavender (Lavandula angustifolia) oil and its primary ingredient (linalool) have postsynaptic nonatropine-like spasmolytic activity in the small intestine [91]. Ocimum gratissimum possesses spasmolytic actions similar to those of atropine [5]. Leaf extracts of Salvia cinnabarina have nonspecific spasmolytic effects in the small intestine [139]. Laminaceae (Satureja hortensis) essential oil has in vitro antispasmodic effects and in vivo antidiarrhea effects [55]. Boswellia serrata has been shown to alleviate experimental ileitis and clinical colitis and to relieve the adverse gastrointestinal changes associated with NSAID administration $[48,85]$. Other plant extracts such as Portulaca oleracea [16], Zataria multiflora boiss [66], Polypodium feei [159], and Marrubiin [33] have known anti-inflammatory and analgesic properties mediated through opioid receptors, nonopioid receptors, and inhibition of prostaglandins. Many of these herbs and herbal extracts have the potential for use in horses with gastrointestinal disease, but studies need to be done on their efficacy and side effects in the horse before they can be recommended.

\section{Acupuncture}

Acupuncture has been shown to have an analgesic effect in acute intestinal colic [82], iatrogenic colic [18], cancerous abdominal pain [177], and enterospasm [62] in human beings. In one human study involving 14 patients with gastric ulcers, acupuncture treatment reduced gastric acid secretion and alleviated ulcer-related pain, with pain relief lasting for longer than 18 months in more than half of the patients [151]. Acupuncture may be less effective against pain because of ischemia [6]. Because acupuncture may also be useful in managing gastrointestinal dysfunction [32], it may become a useful adjunctive tool for treatment of horses with abdominal pain; however, much research has yet to be done in this field.

\section{The future}

New drugs, drug combinations, and routes of administration are rapidly changing the picture of pain management. In people, bupivacaine has been 
used intraperitoneally to relieve postoperative ileus and pain [131], and intraperitoneal lidocaine plus an NSAID provided better analgesia and faster return of bowel function than intraperitoneal lidocaine plus the same NSAID given intravenously [40]. In a mouse peritonitis model, intraperitoneal morphine provided significant analgesia, although intravenous morphine did not, suggesting that peripheral receptors play an important role in inflammatory pain [129]. Ropivacaine gel has been applied rectally for the treatment of active distal ulcerative colitis in people [3], and a "GI cocktail," a combination of oral lidocaine and antacids, is commonly used in the emergency room treatment of upper abdominal pain [171]. Clonidine, an $\alpha_{2}-$ adrenergic agonist more commonly used for its antihypertensive effects, is showing promise as an effective analgesic agent for abdominal surgery in people $[31,160]$. Used intrathecally, clonidine provides analgesia without motor blockade [107]. More drastic measures such as neurolytic celiac plexus blocks have been used as adjunctive analgesia for upper abdominal pain in people [174].

An opioid antagonist in development seems to be capable of preventing morphine-related transit time delays without altering the analgesic effects of morphine [92]. Alternatively, peripherally acting kappa agonists such as fedotozine, which prevent visceral pain, are enhanced in inflammatory conditions and may actually stimulate gastrointestinal motility $[8,60]$. Research in horses suggests that such drugs should be effective and may be associated with minimal locomotor stimulation and gastrointestinal changes [78,137]. Tramadol is a synthetic, centrally acting, weak opioid agonist (one tenth the potency of morphine) commonly used in Europe for postoperative pain in people because of its lack of respiratory depression, decreased sedative effects, negligible abuse potential, and variety of formulations (oral, rectal, and parenteral forms administered intravenously or intramuscularly). Comparative studies have found tramadol to be more effective than NSAIDs for the control of postoperative pain in people [89]. Oral tramadol was compared with oral morphine in human patients with pancreatitis, and both were found to offer adequate analgesia; however, tramadol caused less disturbance in gastrointestinal function and was the preferred analgesic of a greater number of subjects [173]. Tramadol has been shown to be effective in horses when administered epidurally [119]. The effect of oral or parenteral tramadol on the equine gastrointestinal tract remains to be studied, but the results in human studies make tramadol a feasible possibility for the management of gastrointestinal pain in horses.

In addition to being used in the form of transdermal patches, opioids may be administered rectally, vaginally, or sublingually, opening up potential avenues for chronic pain relief $[122,132]$. A multivesicular, liposome-based, sustained-release preparation of morphine administered epidurally to dogs also resulted in extended duration of analgesia without an increase in side effects [178]. 
Research on the receptors involved in pain sensation has led to the development of new drugs and new applications [60]. Cannabinoids are effective analgesics and anti-inflammatory agents in other species, and some are available orally. These drugs offer similar potency to morphine but with longer duration and less significant gastrointestinal side effects [29]. NSAIDs combined with a nitric oxide donor may provide immediate gastric protection through the vasodilatory effects of the nitric oxide [169]. DL-phenylalanine seems to potentiate the effects of opioids through upregulation of the endogenous analgesia system and may be useful in the management of chronic gastrointestinal pain (e.g., gastric ulcers) [141]. Serotonin antagonists and octreotide have proven useful for the treatment of visceral pain in people [60]. Drugs belonging to the methyl-imidazolyl N-acylhydrazone class and leukotriene $\mathrm{D}_{4}$ receptor antagonists are being evaluated in animals for their nociceptive abilities [41,49].

\section{Summary}

Choice of an analgesic for gastrointestinal pain requires consideration of the cause of the pain, desired duration of pain relief, need for sedation, and potential side effects and toxicity, particularly in light of other drugs being used and effects on the gastrointestinal tract. It is imperative that close monitoring be continued to ensure that surgical lesions or worsening conditions are detected. Recent research in the field may lead to new drugs, drug combinations, and avenues of treatment that minimize the side effects of these drugs while maximizing their efficacy.

\section{References}

[1] Ahn H, Bronge A, Johansson K, et al. Effect of continuous postoperative epidural analgesia on intestinal motility. Br J Surg 1988;75:1176-8.

[2] Ala-Kokko TI, Pienimaki P, Lampela E, et al. Transfer of clonidine and dexmedetomidine across the isolated perfused human placenta. Acta Anaesthesiol Scand 1997;41: 313-9.

[3] Arlander E, Ost A, Stahlberg D, et al. Ropivacaine gel in active distal ulcerative colitis and proctitis - a pharmacokinetic and exploratory clinical study. Aliment Pharmacol Ther 1996;10:73-81.

[4] Asai T, Mapleson WW, Power I. Differential effects of clonidine and dexmedetomidine on gastric emptying and gastrointestinal transit in the rat. Br J Anaesth 1997;78:301-7.

[5] Aziba PI, Bass D, Elegbe Y. Pharmacological investigation of Ocimum gratissimum in rodents. Phytother Res 1999;13:427-9.

[6] Barlas P, Lowe AS, Walsh DM, et al. Effect of acupuncture upon experimentally induced ischemic pain: a sham-controlled single-blind study. Clin J Pain 2000;16:25-64.

[7] Betley M, Sutherland SF, Gregoricka MJ, et al. The analgesic effect of ketoprofen for use in treating equine colic as compared to flunixin meglumine. Equine Pract 1991;13:11-6.

[8] Bonaz B, Riviere PJ, Sinniger V, et al. Fedotozine, a kappa-opioid agonist, prevents spinal and supraspinal Fos expression induced by a noxious visceral stimulus in the rat. Neurogastroenterol Motil 2000;12:135-47. 
[9] Breuhaus BA, DeGraves FJ, Honore EK, et al. Pharmacokinetics of ibuprofen after intravenous and oral administration and assessment of safety of administration to healthy foals. Am J Vet Res 1999;60:1066-73.

[10] Brockway MS, Bannister J, McClure JH, et al. Comparison of extradural ropivacaine and bupivacaine. Br J Anaesth 1991;66:31-7.

[11] Brown DR, Miller RJ. Adrenergic mediation of the intestinal antisecretory action of opiates administered into the central nervous system. J Pharmacol Exp Ther 1984;231: $114-9$.

[12] Bueno AC, Seahorn TL, Moore RM. Diagnosis and treatment of right dorsal colitis in horses. Compend Contin Educ Pract Vet 2000;22:173-80.

[13] Bueno AC, Cornick-Seahorn J, Seahorn T, et al. Cardiopulmonary and sedative effects of intravenous administration of low doses of medetomidine and xylazine to adult horses. Am J Vet Res 1999;60:1371-6.

[14] Campbell NB, Blikslager AT. The role of cyclooxygenase inhibitors in repair of ischaemic-injured jejunal mucosa in the horse. Equine Vet J 2000; (Suppl 32):59-64.

[15] Carrick JB, Papich MG, Middleton DM, et al. Clinical and pathological effects of flunixin meglumine administration to neonatal foals. Can J Vet Res 1989;53:195-201.

[16] Chan K, Islam MW, Kamil M, et al. The analgesic and anti-inflammatory effects of Portulaca oleracea L. subsp Sativa (Haw.) Celak. J Ethnopharmacol 2000;73:445-51.

[17] Chang EB, Field M, Miller RJ. $\alpha 2$-adrenergic receptor regulation of ion transport in rabbit ileum. Am J Physiol 1982;242:G237-42.

[18] Cheng Q. Remission of abdominal colic during enteroscopy by injecting vitamin K3 into Zusanli (ST 36) acupoint. J Trad Chin Med 2000;20:271-2.

[19] Christie MJ, Connor M, Vaughan CW, et al. Cellular actions of opioids and other analgesics: implications for synergism in pain relief. Clin Exp Pharmacol Physiol 2000; 27:520-3.

[20] Clark ES, Thompson SA, Becht JL, et al. Effects of xylazine on cecal mechanical activity and cecal blood flow in healthy horses. Am J Vet Res 1988;49:720-3.

[21] Clark JO, Clark TP. Analgesia. Vet Clin North Am Equine Pract 1999;15:705-23.

[22] Clark KW, Baton BS. Combined use of detomidine and romifidine in horses. Equine Vet J 1988;20:331-4.

[23] Collins LG, Tyler DE. Experimentally induced phenylbutazone toxicosis in ponies: description of the syndrome and its prevention with synthetic prostaglandin $E_{2}$. Am J Vet Res 1985;46:1605-15.

[24] Collins SM. The immunomodulation of enteric neuromuscular function: implications for motility and inflammatory disorders. Gastroenterology 1996;111:1683-99.

[25] Covino BG. Toxicity and systemic effects of local anesthetic agents. In: Strichartz GR, editor. Local Anesthetics. Berlin: Springer-Verlag; 1987. p. 187-212.

[26] Crews JC, Hord AH, Denson DD, et al. A comparison of the analgesic efficacy of $0.25 \%$ levobupivacaine combined with $0.005 \%$ morphine, $0.25 \%$ levobupivacaine alone, or $0.005 \%$ morphine alone for the management of postoperative pain in patients undergoing major abdominal surgery. Anesth Analg 1999;89:1504-9.

[27] Crisman MV, Sams RA, Irby MH. The disposition of phenylbutazone in lactating mares and its effect on nursing foals. In: Proceedings of the 35th Annual Convention of the American Association of Equine Practitioners, Boston, 1989. p. 127-131.

[28] Crisman MV, Wilcke JR, Sams RA, et al. Concentrations of phenylbutazone and oxyphenbutazone in post-parturient mares and their neonatal foals. J Vet Pharmacol Ther 1991; 14:330-4.

[29] Dajani EZ, Larsen KR, Taylor J, et al. 1',1'-Dimethylheptyl-delta-8-tetrahydrocannabinol-11-oic acid: a novel, orally effective cannabinoid with analgesic and anti-inflammatory properties. J Pharmacol Exp Ther 1999;291:31-8.

[30] Davis LE. Review of the clinical pharmacology of the equine digestive system. J Equine Med Surg 1977;1:27-35. 
[31] Decock M, Gautier P, Pavlopoulou A, et al. Epidural clonidine or bupivacaine as the sole analgesic agent during and after abdominal surgery: a comparative study. Anesthesiology 1999;90:1354-62.

[32] Deihl DL. Acupuncture for gastrointestinal and hepatobiliary disorders: A review. J Altern Complement Med 1999;5:27-45.

[33] De Jesus RA, Cechenil-Filho V, Oliveira AE, et al. Analysis of the antinociceptive properties of marrubiin isolated from Marrubium vulgare. Phytomedicine 2000;7:111-5.

[34] Doherty TJ, Frazier DL. Effect of intravenous lidocaine on halothane minimum alveolar concentration in ponies. Equine Vet J 1998;30:300-3.

[35] Doherty TJ, Geiser DR, Rohrbach BW. Effect of high volume epidural morphine, ketamine and butorphanol on halothane minimum alveolar concentration in ponies. Equine Vet J 1997;29:370-3.

[36] Doherty TJ, Andrews FM, Provenza MK, et al. The effect of sedation on gastric emptying of a liquid marker in ponies. Vet Surg 1999;28:375-9.

[37] Dubois RN, Abramson SB, Crofford L, et al. Cyclooxygenase in biology and disease. FASEB J 1998;12:1063-73.

[38] Edens LM, Cargile JL. Medical management of colic. In: Robinson NE, editor. Current therapy in equine medicine, 4th edition. Philadelphia: WB Saunders; 1997. p. $182-91$

[39] Eisenach JC, Lavand'homme P, Tong C, et al. Antinoceptive and hemodynamic effects of a novel alpha2-adrenergic agonist, MPV-2426, in sheep. Anesthesiology 1999;91: $1425-36$.

[40] Elhakim M, Amine H, Kamel S, et al. Effects of intraperitoneal lidocaine combined with intravenous or intraperitoneal tenoxicam on pain relief and bowel recovery after laparoscopic cholecystectomy. Acta Anaesthesiol Scand 2000;44:929-33.

[41] Figueiredo JM, Camara CA, Amarante EG, et al. Design and synthesis of novel potent antinociceptive agents: methyl-imidazolyl N-acylhydrazone derivatives. Bioorg Med Chem 2000;8:2243-8.

[42] Foster RH, Markham A. Levobupivacaine: a review of its pharmacology and use as a local anesthetic. Drugs 2000;59:551-79.

[43] Freeman DE. Effects of phenylbutazone on short-circuit current in equine right dorsal colon in vitro. In: Proceedings of the Sixth Equine Colic Research Symposium. Athens (GA): University of Georgia; 1998. p. 26.

[44] Fuentes VO. Sudden death in a stallion after xylazine medication. Vet Rec 1978;102:106.

[45] Gaffney GR, Williamson HE. Effect of indomethacin and meclofenamate on canine mesenteric and celiac blood flow. Res Commun Chem Pathol Pharmacol 1979;25:165-8.

[46] Geisler DR. Chemical restraint and analgesia in the horse. Vet Clin North Am Equine Pract 1990;6:495-512.

[47] Geor RJ. Acute renal failure. In: Robinson NE, editor. Current therapy in equine medicine, 4th edition. Philadelphia: WB Saunders; 1997. p. 472-6.

[48] Gerhardt H, Seifert F, Buvari P, et al. Therapy of active Crohn disease with Boswellia serrata extract H 15. Z Gastroenterol 2001;39:11-7.

[49] Gok S, Onal A, Cinar MG, et al. The antinociceptive effect of leukotriene $\mathrm{D}_{4}$ receptor antagonist, MK-571, in mice: possible involvement of opioidergic mechanism. Eur J Pharmacol 1999;386:195-200.

[50] Gray GW, Yamo BL. A study of the actions of methampyrone and of a commercial intestinal extract preparation on intestinal motility. Am J Vet Res 1975;36:201-8.

[51] Greene SA, Thurmon JC. Xylazine - a review of its pharmacology and use in veterinary medicine. J Vet Pharmacol Ther 1988;11:295-313.

[52] Gregoricka MJ, Busch KR, Pollet RA. Clinical evaluation of ketoprofen: a new nonsteroidal anti-inflammatory drug for use in horses. In: Proceedings of the 37th Annual Convention of the American Association of Equine Practitioners, San Francisco, 1991. p. 19-26. 
[53] Groudine SB, Fisher HAG, Kaufman RP, et al. Intravenous lidocaine speeds the return of bowel function, decreases postoperative pain, and shortens hospital stay in patients undergoing radical retropubic prostatectomy. Anesth Analg 1998;86:235-9.

[54] Grubb TL, Muir III WW, Bertone AL, et al. Use of yohimbine to reverse prolonged effects of xylazine hydrochloride in a horse being treated with chloramphenicol. JAVMA 1997;210:1771-3.

[55] Hajhashemi V, Sadraei H, Ghannadi AR, et al. Antispasmodic and anti-diarrhoeal effect of Satureja hortensis essential oil. J Ethnopharmacol 2000;71:187-92.

[56] Hall JE, Uhrich TD, Barney JA, et al. Sedative, amnestic and analgesic properties of small-dose dexmedetomidine infusions. Anesth Analg 2000;90:669-705.

[57] Hamm D, Turchi P, Jochle W. Sedative and analgesic effects of detomidine and romifidine in horses. Vet Rec 1995;136:324-7.

[58] Hamm D, Turchi P, Johnson JC, et al. Determination of an effective dose of eltenac and its comparison with that of flunixin meglumine in horses after experimentally induced carpitis. Am J Vet Res 1997;58:298-302.

[59] Hansten PD, Horn JR. Drug Interactions and Updates Quarterly. Vancouver: Applied Therapeutics; 1993.

[60] Hasler WL. Visceral analgesia: an emerging concept for managing functional gastrointestinal disease. Gastroenterology 1998;115:1023-4.

[61] Hay WP, Moore JN. Management of pain in horses with colic. Compend Contin Educ Pract Vet 1997;19:987-90.

[62] He Y. Enterospasm treated by pressure on jimai acupoint. J Trad Chin Med 1990;10:19.

[63] Hills JM, Aaronson PI. The mechanism of action of peppermint oil on gastrointestinal smooth muscle. An analysis using patch clamp electrophysiology and isolated tissue pharmacology in rabbit and guinea pig. Gastroenterology 1991;101:55-65.

[64] Hoffman PE. Clinical evaluation of xylazine as a chemical restraining agent, sedative, and analgesic in horses. JAVMA 1974;164:42-5.

[65] Holte K, Kehlet H. Postoperative ileus: a preventable event. Br J Surg 2000;87:1480-93.

[66] Hosseinzadeh H, Ramezani M, Salmani G. Antinociceptive, anti-inflammatory and acute toxicity effects of Zataria multiflora boiss extracts in mice and rats. $\mathrm{J}$ Ethnopharmacol 2000;73:379-85.

[67] Hubbell JAE, Hinchcliff KW, Schmall LM, et al. Cardiorespiratory and metabolic effects of xylazine, detomidine, and a combination of xylazine and acepromazine administered after exercise in horses. Am J Vet Res 1999;60:1271-9.

[68] Hunt JM, Gerring EL. The effect of prostaglandin $\mathrm{E}_{1}$ on motility of the equine gut. J Vet Pharmacol Ther 1985;8:165-73.

[69] Hunt JM, Gerring EL. Effects of autonomic agonists on equine gastrointestinal electromechanical activity. In: Proceedings of the Second Equine Colic Research Symposium, Athens, GA, 1986. p. 210-13.

[70] Jaraiz MV, Rodriguez C, San Andres MD, et al. Disposition and tolerance of suxibuzone in horses. Equine Vet J 1999;31:411-6.

[71] Jensen RC, Fischer JH, Cwik MJ. Effect of age and training status on pharmacokinetics of flunixin meglumine in Thoroughbreds. Am J Vet Res 1990;51:591-4.

[72] Johnson CB, Taylor PM, Young SS, et al. Postoperative analgesia using phenylbutazone, flunixin or carprofen in horses. Vet Rec 1993;133:336-8.

[73] Jones EW, Hamm D. Comparative efficacy of phenylbutazone and naproxen in induced equine myositis. J Equine Med Surg 1978;2:341-7.

[74] Jorgensen H, Fomsgaard JS, Dirks J, et al. Effect of continuous epidural $0.2 \%$ ropivacaine vs $0.2 \%$ bupivacaine on postoperative pain, motor block and gastrointestinal function after abdominal hysterectomy. Br J Anaesth 2000;84:826-7.

[75] Kalff JC, Schraut WH, Simmons RL, et al. Surgical manipulation of the gut elicits an intestinal muscularis inflammatory response resulting in postsurgical ileus. Ann Surg 1998; 228:652-63. 
[76] Kalpravidh M, Lumb WV, Wright M, et al. Analgesic effects of butorphanol in horses: Dose-response studies. Am J Vet Res 1984;45:211-6.

[77] Kalpravidh M, Lumb WV, Wright M, et al. Effects of butorphanol, flunixin, levorphanol, morphine and xylazine in ponies. Am J Vet Res 1984;45:217-23.

[78] Kamerling S, Wood T, DeQuick D, et al. Narcotic analgesics, their detection and pain measurement in the horse: A review. Equine Vet J 1989;21:4-12.

[79] Kamerling SG, Hamra JG, Bagwell CA. Naloxone-induced abdominal distress in the horse. Equine Vet J 1990;22:241-3.

[80] Katila T, Oijala M. The effect of detomidine (Domosedan) on the management of equine pregnancy and foetal development: ten cases. Equine Vet J 1988;20:323-5.

[81] King JN, Gerring EL. Antagonism of endotoxin-induced disruption of equine bowel motility by flunixin and phenylbutazone. Equine Vet J 1989; (Suppl 7):38-42.

[82] Kohn CW, Muir III WW. Selected aspects of the clinical pharmacology of visceral analgesics and gut motility modifying drugs in the horse. J Vet Intern Med 1988;2:85-91.

[83] Kolesnikov YA, Chereshnev I, Pasternak GW. Analgesic synergy between topical lidocaine and topical opioids. J Pharmacol Exp Ther 2000;295:546-51.

[84] Kopacz DJ, Allen HW, Thompson GE. A comparison of epidural levobupivacaine $0.75 \%$ with racemic bupivacaine for lower abdominal surgery. Anesth Analg 2000;90:642-8.

[85] Krieglstein CF, Anthoni C, Rijcken EJ, et al. Acetyl-11-keto-beta-boswellic acid, a constituent of an herbal medicine from Boswellia serrata resin, attenuates experimental ileitis. Int J Colorectal Dis 2001;16:88-95.

[86] Lawrence CJ, Prinzen FW, deLange S. Hemodynamic and coronary vascular effects of dexmedetomidine in the anesthetized goat. Acta Anaesthesiol Scand 1997;41:830-6.

[87] LeBlanc MM, Hubbell JAE, Smith HC. The effects of xylazine hydrochloride on intrauterine pressure in the cow. Theriogenology 1984;21:681-90.

[88] Lees P, McKellar Q, May SA, et al. Pharmacodynamics and pharmacokinetics of carprofen in the horse. Equine Vet J 1994;26:203-8.

[89] Lehmann KA. Tramadol in acute pain. Drugs 1997;53(suppl 2):25-33.

[90] Lester GD, Merritt AM, Neuwirth L, et al. Effect of $\alpha_{2}$-adrenergic, cholinergic, and nonsteroidal anti-inflammatory drugs on myoelectric activity of ileum, cecum, and right ventral colon and on cecal emptying of radiolabeled markers in clinically normal ponies. Am J Vet Res 1998;59:320-7.

[91] Lis-Balchin M, Hart S. Studies on the mode of action of the essential oil of lavender (Lavandula angustifolia P. miller). Phytother Res 1999;13:540-2.

[92] Liu SS, Hodgson PS, Carpenter RI, et al. ADL 8-2698, a trans-3,4-dimethyl-4-(3hydroxyphenyl) piperidine, prevents gastrointestinal effects of intravenous morphine without affecting analgesia. Clin Pharmacol Ther 2001;69:66-71.

[93] Lowe JE. Xylazine, pentazocine, meperidine, and dipyrone for relief of balloon induced equine colic: A double blind comparative evaluation. J Equine Med Surg 1978;2:286-91.

[94] Lowe JE, Hilfiger J. Analgesic and sedative effects of detomidine compared to xylazine in a colic model using I.V. and I.M. routes of administration. Acta Vet Scand 1986;82:85-95.

[95] Lowe JE, Sellers AF, Brondum J. Equine pelvic flexure impaction. A model used to evaluate motor events and compare drug response. Cornell Vet 1980;70:401-12.

[96] Luukkanen L, Katila T, Koskinen E. Some effects of multiple administration of detomidine during the last trimester of equine pregnancy. Equine Vet J 1997;29:400-3.

[97] MacAllister CG, Morgan SJ, Borne AT, et al. Comparison of the adverse effects of phenylbutazone, flunixin meglumine, and ketoprofen in horses. JAVMA 1993;202:71-7.

[98] MacGregor RR, Thorner RE, Wright DM. Lidocaine inhibits granulocyte adherence and prevents granulocyte delivery to inflammatory sites. Blood 1980;56:203-9.

[99] MacKay RJ, Daniels CA, Bleyaert HF, et al. Effects of eltenac in horses with induced endotoxaemia. Equine Vet J 2000; (Suppl 32):26-31.

[100] MacKellar JC. Procaine hydrochloride in the treatment of spasmodic colic in horses. Vet Rec 1967;80:444-5. 
[101] Macoris DG, Gandolfi W. Intestinal transit in equine: effect of therapy with flunixin meglumine, combination dipyrone-hioscine, and mineral oil. In: Proceedings of the Sixth Equine Colic Research Symposium, Athens, GA, 1998, p. 27.

[102] Malone ED. Intravenous lidocaine: An unusual use for a common drug. MERC News 2001;1:5-6.

[103] Malone ED, Kannan MS. Effects of intestinal ischemia on in vitro activity of adjacent jejunum in samples obtained from ponies. Am J Vet Res 2001;62:1973-8.

[104] Malone ED, Turner TA, Wilson JH. Intravenous lidocaine for the treatment of equine ileus. In: Proceedings of the Sixth Equine Colic Research Symposium. Athens (GA): University of Georgia; 1998. p. 42.

[105] Martin S, Farr L, Murray E. Clinical use of detomidine hydrochloride. Equine Pract 1995;17:21-9.

[106] Matthews NS, Peck KE, Mealy KL. Transdermal fentanyl: absorption and plasma levels in horses. In: Proceedings of the Sixth International Congress of Veterinary Anesthesiology. Thessaloniki, Greece: Aristotle University of Thessaloniki; 1997. p. 116.

[107] Mercier FJ, Dounas M, Bouaziz H. The effect of adding a minidose of clonidine to intrathecal sufentanil for labor analgesia. Anesthesiology 1998;89:594-601.

[108] Merritt AM, Burrow JA, Hartless CS. Effect of xylazine, detomidine, and a combination of xylazine and butorphanol on equine duodenal motility. Am J Vet Res 1998;59:619-23.

[109] Merritt AM, Campbell-Thompson ML, Lowrey S. Effect of xylazine treatment on equine proximal gastrointestinal tract myoelectrical activity. Am J Vet Res 1989;50:945-9.

[110] Merritt AM, Campbell-Thompson ML, Lowrey S. Effect of butorphanol on equine antroduodenal motility. Equine Vet J 1989; (Suppl 7):21-3.

[111] Merritt AM, MacKay RJ, Burrow JR, et al. Anti-endotoxic effect of ketoprofen in horses [abstract]. In: Proceedings of the Fourth Equine Colic Research Symposium, Athens, GA; 1991. p. 56.

[112] Mickelfield GH, Greving I, May B. Effects of peppermint oil and caraway oil on gastroduodenal motility. Phytother Res 2000;14:20-3.

[113] Moll HD, Slone DE. Perineal lacerations and rectovestibular fistulas. In: Wolfe DW, Moll HD, editors. Large animal urogenital surgery. Baltimore: Williams \& Wilkins; 1999. p. 103-8.

[114] Moore JN. Management of pain and shock in equine colic. Compend Contin Educ Pract Vet 1985;7(Suppl):S169-75.

[115] Muir WW. Anesthesia and pain management in horses. Equine Vet Educ 1998;10:335-40.

[116] Muir WW, Robertson JT. Visceral analgesia: effects of xylazine, butorphanol, meperidine, and pentazocine in horses. Am J Vet Res 1985;46:2081-4.

[117] Muir WW, Robertson JT, Wade A, et al. Pharmacological effects of intravenous butorphanol tartrate in horses. In: Proceedings of the Equine Colic Research Symposium. Athens, GA; 1982. p. 223-4.

[118] Nakamura K, Hara S, Tomizawa N. The effects of medetomidine and xylazine on gastrointestinal motility and gastrin release in the dog. J Vet Pharmacol Ther 1997;20:290-5.

[119] Natalini CC, Robinson EP. Evaluation of the analgesic effects of epidurally administered morphine, alfentanil, butorphanol, tramadol and U0488H in horses. Am J Vet Res 2000; 61:1579-86.

[120] Naylor JM, Garven E, Fraser L. A comparison of romifidine and xylazine in foals: the effects on sedation and analgesia. Equine Vet Educ 1997;9:329-34.

[121] Nieto JE, Rakestraw PC, Snyder JR, et al. In vitro effects of erythromycin, lidocaine, and metoclopramide on smooth muscle from the pyloric antrum, proximal portion of the duodenum, and middle portion of the jejunum in horses. Am J Vet Res 2000;61:413-9.

[122] Ostrop NJ, Lamb J, Reid G. Intravaginal morphine: an alternative route of administration. Pharmacotherapy 1998;18:863-5.

[123] Palmoski M, Brandt K. Effects of some nonsteroidal antiinflammatory drugs on proteoglycan metabolism and organization in canine articular cartilage. Arthritis Rheum 1980;23:1010-20. 
[124] Paneuf LP, Grivel ML, Ruckebusch Y. Electromyoenterography during normal gastrointestinal activity, painful or non-painful colic and morphine analgesia in the horse. Can J Comp Med 1972;36:138-44.

[125] Paradis MR. Prokinetic drugs in the treatment of proximal enteritis. Compend Contin Educ Pract Vet 1999;21:1147-9.

[126] Pascoe PJ, Dyson DH. Analgesia after lateral thoracotomy in dogs: epidural morphine vs intercostal bupivacaine. Vet Surg 1993;22:141-7.

[127] Pippi NL, Lumb WV. Objective tests of analgesic drugs in ponies. Am J Vet Res 1979;40: $1082-6$.

[128] Plumb DC. Veterinary drug handbook, 2nd edition. Ames: Iowa State University Press; 1995.

[129] Reichert JA, Daughters RS, Rivard R, et al. Peripheral and preemptive opioid antinociception in a mouse visceral pain model. Pain 2001;89:221-7.

[130] Rimbäck G, Cassuto J, Tollesson PO. Treatment of postoperative paralytic ileus by intravenous lidocaine infusion. Anesth Analg 1990;70:414-9.

[131] Rimbäck G, Cassuto J, Faxen A, et al. Effect of intra-abdominal bupivacaine instillation on postoperative colonic motility. Gut 1986;27:170-5.

[132] Ripamonti C, Bruera E. Rectal, buccal, and sublingual narcotics for the management of cancer pain. J Palliat Care 1991;7:30-5.

[133] Roberts MC, Argenzio A. Effects of amitraz, several opiate derivatives and anticholinergic agents on intestinal transit in ponies. Equine Vet J 1986;18:256-60.

[134] Robertson JT, Muir WW. A new analgesic drug combination in the horse. Am J Vet Res 1983;44:1667-9.

[135] Roger T, Ruckebusch Y. Colonic $\alpha_{2}$-adrenoceptor-mediated responses in the pony. J Vet Pharmacol Ther 1987;10:310-8.

[136] Roger T, Ruckebusch Y. Pharmacological modulation of postprandial colonic motor activity in the pony. J Vet Pharmacol Ther 1987;10:273-82.

[137] Roger T, Bardon T, Ruckebusch Y. Comparative effects of mu and kappa opiate agonists on the cecocolic motility in the pony. Can J Vet Res 1994;58:163-6.

[138] Rohde C, Anderson DE, Bertone AL, et al. Effects of phenylbutazone on bone activity and formation in horses. Am J Vet Res 2000;61:537-43.

[139] Romussi G, Ciarallo G, Bisio A, et al. A new diterpenoid with antispasmodic activity from Salvia cinnabarina. Planta Med 2001;67:153-5.

[140] Ross MW, Donawick WJ, Sellers AJ. Normal and altered cecocolic motility patterns in ponies [abstract]. Vet Surg 1985;14:63.

[141] Russell AL, McCarty MF. DL-phenylalanine markedly potentiates opiate analgesia - -an example of nutrient/pharmaceutical up-regulation of the endogenous analgesia system. Med Hypotheses 2000;55:283-8.

[142] Rutkowski JA, Eades SC, Moore JN. Effects of xylazine butorphanol on cecal arterial blood flow, cecal mechanical activity, and systemic hemodynamics in horses. Am J Vet Res 1991;52:1153-8.

[143] Santos AC, Arthur GR, Wlody D, et al. Comparative systemic toxicity of ropivacaine and bupivacaine in nonpregnant and pregnant ewes. Anesthesiology 1995;82:734 40.

[144] Sayegh AI, Adams SB, Peter AT, et al. Equine rectal tears: Causes and management. Compend Contin Educ Pract Vet 1996;18:1131-9.

[145] Scanlon JW, Brown WE, Weiss JB, et al. Neurochemical responses of newborn infants after maternal epidural anesthesia. Anesthesiology 1974;40:121-8.

[146] Schaub RG, Moore JN, Garner HE, et al. Pulmonary vascular damage in the pony induced by endotoxin: effect of lidocaine. In: Proceedings of the Equine Endotoxemia and Laminitis Symposium, American Association of Equine Practitioners Newsletter, Atlanta, GA., 1982. Golden (CO): American Association of Equine Practitioners. p. 87-96.

[147] Sellon DC, Monroe VL, Roberts MC, et al. Pharmacokinetics and adverse effects of butorphanol administered by single intravenous injection or continuous intravenous infusion in horses. Am J Vet Res 2001;62:183-9. 
[148] Semrad SD, Sams RA, Harris ON, et al. Effects of concurrent administration of phenylbutazone and flunixin meglumine on pharmacokinetic variables and in vitro generation of thromboxane $\mathrm{B}_{2}$ in mares. Am J Vet Res 1993;54:1901-5.

[149] Semrad SD, Hardee GE, Hardee MM, et al. Low dose flunixin meglumine: effects on eicosanoid production and clinical signs induced by experimental endotoxaemia in horses. Equine Vet J 1987;19:201-6.

[150] Shnider SM, Way EL. Plasma levels of lidocaine (Xylocaine) in mother and newborn following obstetrical conduction anesthesia: clinical applications. Anesthesiology 1968;29:951-8.

[151] Sodipo JOA, Falaiye JM. Acupuncture and gastric acid studies. Am J Chin Med 1979;7: 356-61.

[152] Sojka JE, Adams SB, Lamar CH, et al. Effect of butorphanol, pentazocine, meperidine, or metoclopramide on intestinal motility in female ponies. Am J Vet Res 1988;49:527-9.

[153] Soma LR, Uboh CE, Rudy JA, et al. Plasma and synovial fluid kinetics, disposition, and urinary excretion of naproxen in horses. Am J Vet Res 1995;56:1075-80.

[154] Spackman DR, McLeod ADM, Prineas SN, et al. Effect of epidural blockade on indicators of splanchnic perfusion and gut function in critically ill patients with peritonitis: a randomised comparison of epidural bupivacaine with systemic morphine. Intensive Care Med 2000;26:1638-45.

[155] Stick JA, Chou CC, Derksen FA, et al. Effects of xylazine on equine intestinal vascular resistance, motility, compliance and oxygen consumption. Am J Vet Res 1985;46:31-5.

[156] Stick JA, Arden WA, Chou CC, et al. Effects of flunixin meglumine on jejunal blood flow, motility, and oxygen consumption in ponies. Am J Vet Res 1988;49:1173-8.

[157] Stick JA, Loeffler BS, Arden WA, et al. Effects of butorphanol tartrate on arterial pressure, jejunal blood flow, vascular resistance, $\mathrm{O}_{2}$ extraction, and $\mathrm{O}_{2}$ uptake in halothaneanesthetized ponies. Am J Vet Res 1989;50:1202-6.

[158] Stout RC, Priest GT. Clinical experience using butorphanol tartrate for relief of abdominal pain in the horse. In: Proceedings of the Second Equine Colic Research Symposium, Athens, GA; 1986. p. 68-70.

[159] Subarnas A, Wagner H. Analgesic and anti-inflammatory activity of the proanthocyanidin shellegueain A from Polypodium feei METT. Phytomedicine 2000;7:401-5.

[160] Sung CS, Lin SH, Chan KH, et al. Effect of oral clonidine premedication on perioperative hemodynamic response and postoperative analgesic requirement for patients undergoing laparoscopic cholecystectomy. Acta Anaesthesiol Scand 2000;38:23-9.

[161] Sysel AM, Pleasant RS, Jacobson JD, et al. Efficacy of epidural combination of morphine and detomidine in alleviating experimentally induced hindlimb lameness in horses. Vet Surg 1996;25:511-8.

[162] Taylor PM, Bennett RC, Brearley JC, et al. Comparison of detomidine and romifidine as premedicants before ketamine and halothane anesthesia in horses undergoing elective surgery. Am J Vet Res 2001;62:359-63.

[163] Templeton CB, Bottoms GD, Fessler JF, et al. Endotoxin-induced hemodynamic and prostaglandin changes in ponies: Effects of flunixin meglumine, dexamethasone, and prednisolone. Circ Shock 1987;23:231-40.

[164] Tulimat MA, Ishiguchi T, Kurosawa S, et al. The inhibitory effect of herbal medicine Dai Kenchu To (DKT) on the colonic motility in rats in vitro. Am J Chin Med 2001;29:111-8.

[165] Valle L, Pol O, Puig MM. Intestinal inflammation enhances the inhibitory effects of opioids on intestinal permeability in mice. J Pharmacol Exp Ther 2001;296:378-87.

[166] Van Hoogmoed L, Rakestraw PC, Snyder JR, et al. In vitro effects of nonsteroidal antiinflammatory agents and prostaglandins $\mathrm{I}_{2}, \mathrm{E}_{2}$, and $\mathrm{F}_{2 \alpha}$ on contractility of taenia of the large colon of horses. Am J Vet Res 1999;60:1004-9.

[167] Vernimb GD, Hennessey PW. Clinical studies on flunixin meglumine in the treatment of equine colic. J Equine Med Surg 1977;1:111-6.

[168] Vutyavanich T, Kraisarin T, Ruangsri R. Ginger for nausea and vomiting in pregnancy: randomized, double-masked, placebo-controlled trial. Obstet Gynecol 2001;17:577-82. 
[169] Wallace JL, Reuter BK, Cirino G. Nitric oxide-releasing non-steroidal anti-inflammatory drugs. A novel approach for reducing gastrointestinal toxicity. J Gastroenterol Hepatol 1994;1(Suppl):S40-4.

[170] Wallin G, Cassuto J, Högström S, et al. Effects of lidocaine infusion on the sympathetic response to abdominal surgery. Anesth Analg 1987;66:1008-13.

[171] Welling LR, Watson WA. The emergency department treatment of dyspepsia with antacids and oral lidocaine. Ann Emerg Med 1990;19:785-8.

[172] White NA. Medical management of the colic patient. In: Proceedings of the 34th Annual Convention of the American Association of Equine Practitioners, 1988. Golden (CO): American Association of Equine Practitioners. p. 81-96.

[173] Wilder-Smith CH, Hill L, Osler W, et al. Effect of tramadol and morphine on pain and gastrointestinal motor function in patients with chronic pancreatitis. Dig Dis Sci 1999; 44:1107-16.

[174] Wong GY, Brown DL. Celiac plexus block for cancer pain. In: Urmey W, editor. Techniques in regional anesthesia and pain management. Philadelphia: WB Saunders; 1997. p. 18-26.

[175] Wood T, Weckman T, Woods WE, et al. Detomidine: a preliminary analysis of its duration of action in the horse by variable interval responding. Equine Vet J 1988;20:320-2.

[176] Woolf CJ, Chong M. Preemptive analgesia - treating postoperative pain by preventing the establishment of central sensitization. Anesth Analg 1993;77:362-79.

[177] Xu S, Liu Z, Xu M. Treatment of cancerous abdominal pain by acupuncture on zusanli (ST 36) - report of 92 cases. J Trad Chin Med 1995;15:189-91.

[178] Yaksh TL, Provencher JC, Rathbun ML, et al. Pharmacokinetics and efficacy of epidurally delivered sustained-release encapsulated morphine in dogs. Anesthesiology 1999;90: $1402-12$.

[179] Yamahara J, Mochizuki M, Rong HQ, et al. The anti-ulcer effect in rats of ginger constituents. J Ethnopharmacol 1988;23:299-304. 